\title{
The effect of organizational justice on knowledge workers' job crafting - - A chain mediation model of psychological ownership and organizational trust
}

\author{
Li Tan \\ Institute of Psychology, Chinese \\ Academy of Sciences, Beijing, \\ P.R.China 100101 \\ Department of Psychology, University \\ of Chinese Academy of Sciences, \\ Beijing, P.R.China 100049 \\ 361136769@qq.com
}

\author{
Zhou Ting \\ Department of Medical Psychology, \\ School of Health Humanities, Peking \\ University, Beijing, P.R.China 100191 \\ zhouting.92@bjmu.edu.cn
}

\author{
Huang Zheng \\ Institute of Psychology, Chinese \\ Academy of Sciences, Beijing, \\ P.R.China 100101 \\ Department of Psychology, University \\ of Chinese Academy of Sciences, \\ Beijing, P.R.China 100049 \\ huangz@psych.ac.cn
}

\begin{abstract}
Based on social exchange theory, this paper explores the driving mechanism of organizational justice on job crafting and the roles of psychological ownership and organizational trust played in their relationship. Based on the valid sample data of 316 knowledge workers, using the structural equation model and bootstrap method to test the sample data, this paper finds that organizational justice has a significant positive impact on knowledge workers' job crafting; Furthermore, psychological ownership and organizational trust plays a chain mediating role between them. Moreover, the mediating effect of psychological ownership is higher than organizational trust.
\end{abstract}

\section{CCS CONCEPTS}

- Applied computing; • Law, social and behavioral sciences; - Psychology;

\section{KEYWORDS}

job crafting, knowledge worker, organizational justice, psychological ownership, organizational trust

ACM Reference Format:

Li Tan, Zhou Ting, and Huang Zheng. 2021. The effect of organizational justice on knowledge workers' job crafting -- A chain mediation model of psychological ownership and organizational trust. In The 2021 12th International Conference on E-business, Management and Economics (ICEME 2021), July 17-19, 2021, Beijing, China. ACM, New York, NY, USA, 6 pages. https://doi.org/10.1145/3481127.3481202

\section{INTRODUCTION}

With the rapid development of the economy, knowledge and technology have increasingly become the core factor of enterprise competition, which also means that knowledge workers occupy

Permission to make digital or hard copies of all or part of this work for personal or classroom use is granted without fee provided that copies are not made or distributed for profit or commercial advantage and that copies bear this notice and the full citation on the first page. Copyrights for components of this work owned by others than ACM must be honored. Abstracting with credit is permitted. To copy otherwise, or republish, to post on servers or to redistribute to lists, requires prior specific permission and/or a fee. Request permissions from permissions@acm.org.

ICEME 2021, fuly 17-19, 2021, Beijing, China

(c) 2021 Association for Computing Machinery.

ACM ISBN 978-1-4503-9006-4/21/07 . \$15.00

https://doi.org/10.1145/3481127.3481202 an increasingly important position, and the competitiveness level of enterprises often depends on the quantity and quality of their knowledge workers. Knowledge workers have high comprehensive quality and outstanding personal ability. They have a strong desire to realize their self-worth. They not only want to obtain material rewards in their work, but also care about the spiritual needs, their labor results often have high added value, but this value is difficult to quantify, and it is difficult for the organization to evaluate and assess [1], therefore managers need advanced management styles to stimulate the initiative of knowledge workers, so that employees can work spontaneously and proactively to design their work to achieve meaning and gain a sense of identity [2], thus creating greater value for the organization Wrzeseniewski \& Dutton (2001) define this bottom-up initiative of employees to change work boundaries as job crafting [3]. A review of studies shows that job crafting has positive and significant effects on employees' job performance, job well-being, work engagement, and creativity [4-9]. Given its important managerial value, research on the antecedent variables of job crating is particularly important, and most studies currently focus on how personal traits and job characteristics moderate the effects on job crafting, but there is a lack of research targeting the influence of organizational environment on job crafting[10], and a lack of examination of deeper mediating mechanisms in the relationship between job crafting and the antecedent variables [11], this paper will explore the path of influence of organizational justice on knowledge workers' job crafting, and provide theoretical references for organizational interventions and guidance of knowledge workers' job crafting.

\section{THEORY AND HYPOTHESIS}

\subsection{Job Crafting}

Workers spontaneously adjust their own work boundaries and responsibilities, which is called job crafting. Job crafting is spontaneous acts from workers, without interference by managers [12]. Wrezsenieski and Dutton [3] proposed that job crafting can be defined from three dimensions: task crafting, relational crafting, cognitive crafting. Task crafting refers to workers spontaneously change the form and number of tasks. Relational crafting emphasizes that workers spontaneously build or improve their own interpersonal relationships, and cognitive crafting focuses on changing 
the view of work. Tims\&Bakker [13] proposed a four-dimensional model of job crafting: increasing social job resources, increasing structural job resources, increasing challenging job demands, and decreasing hindering job demands. These categories focus on the objective perspective of working sources, however, they ignore individual psychological activities. The studies of two schools both have advantages and disadvantages. Wrezsenieski and Dutton are known for analyzing individual behavior and motivation, focusing on outcome variables such as the meaning of work and happiness at work. The Tims school focuses on matching people to jobs and on outcome variables such as job engagement and job performance.

In this paper, we explore the driving mechanism of organizational justice for knowledge workers on job crafting, which is based on a three-dimensional model of task crafting, relational crafting, and cognitive crafting.

\subsection{Knowledge Worker}

Knowledge worker refers to "the person who masters and uses symbols and concepts, and makes use of knowledge or information for working" [14] pioneered by the famous American scholar Peter Drucker. Compared with ordinary workers, knowledge workers have higher personal quality, higher educational background and other abilities. They are no longer the "machinery" that only sells labor power. Instead, they are the core talents of enterprises and have strong competitiveness in the talent market. According to Maslow's demand theory, knowledge workers are eager for higherlevel needs, such as the realization of self-value. Gallup company found that the work effort level of knowledge workers (70 percent) is determined by their sense of self-worth and psychological feelings. In their work, they think more about the sense of achievement and the reward matching their contribution, so they care more about the fairness of the organization [15].

\subsection{Organizational Justice and Job Crafting}

Organizational justice refers to people's inner feeling of justice in an organization [16]. Organizational justice has a significant positive impact on job satisfaction, organizational commitment, organizational citizenship behavior and job performance [17-19].

Researches on organizational justice can be divided into three stages.

In 1965, Adamas et al. put forward the concept of justice in organizational science, which mainly refers to the fairness of salary distribution and focuses on the results of distribution, that is, "distribution justice".

In 1980, Leventhal el al. applied the viewpoint of procedural justice to organizational context and proposed six standards of procedural justice, including consistency rule, unbiased rule, accuracy rule, revisable rule, representative rule, moral and ethical rule [20]. Furthermore, the researchers gradually pay more attention to the issue of "procedural justice". And justice in organizational context is also divided into two categories: (1) The feeling of result or resource allocation justice, that is, distribution justice, and (2) The feeling of justice used to determine outcomes or resource allocation in procedures, that is, procedural justice.

In 1986, Bies and Moag began to pay attention to the influence of interpersonal interaction on the feelings of justice in the process of program execution, which is identified "interactive justice"[21]. In 1993, Greenberg et al. further divided this kind of interactive justice into two situations: (1) "interpersonal justice" refers to whether or to what extent the superior can respect the dignity of employees when implementing the decision-making process, and (2) "information justice" refers to whether or to what extent the superior can transmit information to the employees within the organization, further, explain to employees the reason for using the specific procedures. [22]

In this study, the definition of organizational justice model mainly consults the model proposed by Liu et al. that considers the specific background of China [23]. Our model is analyzed from four dimensions, including distribution justice, procedural justice, leadership justice and information justice.

In fact, employees' demand for organizational justice is a kind of contract with organization, which means the employees' payment is equal to the return of organization. Therefore, organizations have clear distribution system, transparent information, and employees can participate in the decision-making and be respected by the organization. Only in this way can employees believe that "there is a reward for paying", that is, the income of the employees is predictable and open. Based on the social exchange theory, the feeling of organizational justice promotes employees to understand that the more they pay, the more organization returns, which leads to positive behavior in job crafting. Therefore, the following hypothesis is put forward.

H1: Organizational justice has a positive impact on job crafting of knowledge workers.

\subsection{The mediating role of Psychological Ownership}

Psychological ownership is a psychological state in which an individual has a sense of ownership to a target (or part of a target). Pierce et al. [24] explained the source of psychological ownership to a target from three aspects, including the individual investment, the individual understanding, and the individual control. In an organization, employees have the rights to know, control, and profit, because of the arrangement of organization system, position setting, etc. Meanwhile, employees put a lot of time and energy in their working process. Therefore, they increase their control, intimate their understanding, and add personal investment to the organization, resulting in the emergence of psychological ownership [25]. Researches show that psychological ownership often plays a mediating role. Hu et al. [26] find that psychological ownership has a partial mediating effect between internal / external motivation and employee engagement. Li et al. [27] prove that psychological ownership plays a partial mediating role between transformational leadership and subordinate individual responsible behavior. Does psychological ownership mediate a role of organizational justice and job crafting? Liu et al. [28] confirm that psychological ownership has a significant positive correlation with organizational justice. The more organizational justice employees have, the more energy they will put into work to obtain greater returns. While they put more energies into work, they will have a deeper understanding and control over the organization, which greatly enhance their 


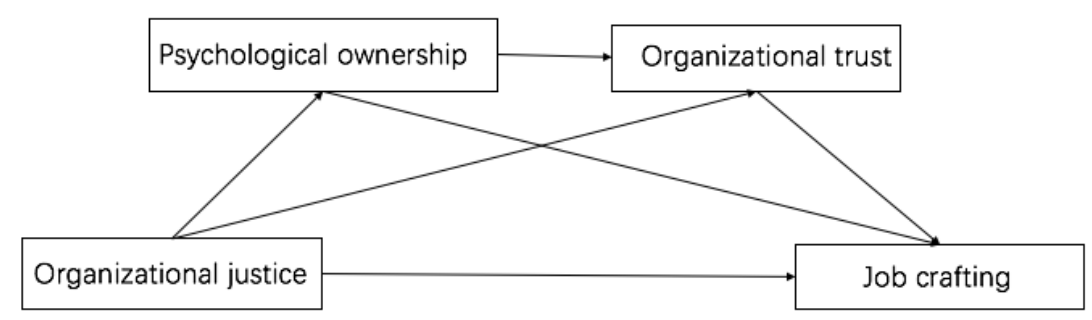

Figure 1: The hypothesis framework

psychological ownership. Psychological ownership encourages individuals to regard the target as a part of themselves and produce positive emotions, which helps stimulate the positive behavior of protecting and making the target better, resulting in job crafting.

H2: Psychological ownership plays a mediating role between organizational justice and job crafting

\subsection{The mediating role of Organizational Trust}

Organizational trust is a very complex social and psychological phenomenon, which has not been uniform defined yet. In theory, there are mainly two views, namely "Inter organizational trust" and "intra organizational trust”. This paper only studies intra organizational trust.

Liu et al. [29] believe that organizational trust refers to the system trust in an organization, the trust of members in the whole organization, and a holistic trust perception. Organizational trust is a trust experience to the whole organization, which is based on the overall impression of members of the organization on the decisions and actions of the management, as well as the impression of organizational rules and the regulations. In this paper, we agree with the views, which says the environment of organizational justice will promote the trust of workers in an organization. Furthermore, Nyhan et al. [30] also find that the feeling of organizational justice has a positive and significant impact on organizational trust. If employees trust organization, believe that organization is fair and can give fair returns in both material and spiritual aspects, they will change their work boundaries and take responsibilities, which results in a meaningful work. Therefore, the following hypothesis is put forward.

H3: Organizational trust plays a mediating role between organizational justice and job crafting

\subsection{The Chain mediating role of Psychological Ownership and Organizational Trust}

Psychological ownership is a feeling of individual ownership to the target. As for workers, when they feel that "the company is their own", it will make them believe in their organization. Furthermore, psychological ownership has a positive impact on organizational trust, which further affects the behavior of job crafting. Therefore, the following hypothes is put forward.

H4: Psychological ownership and organizational trust play a chain mediating role between organizational justice and job crafting.
In conclusion, the theoretical model of our study is shown in Figure 1

\section{METHODS}

\subsection{Subjects}

The sample of this study is obtained by issuing electronic questionnaire to knowledge workers of nearly 100 companies in China. Knowledge workers investigated in our study are the key employees (such as technicians, managers, etc.), and all of them have at least bachelor degrees. In total, 455 questionnaires were collected, and 316 valid questionnaires were obtained with an effective recovery rate of $69.5 \%$.

As shown in Table 1, there are more male knowledge workers, with a proportion of $59.8 \%$. Most of the knowledge workers $(72.1 \%)$ are from 26 to 35 years old. Among the investigated workers, $66.5 \%$ have bachelor degrees. Moreover, there are more technicians than managers, with a proportion of $75.6 \%$.

\subsection{Measures}

The scales used in this paper are mature scales that have been empirically tested.

3.2.1 Scale of Organizational Justice. The scale of organizational justice used is developed by Liu et al. The table totally contains 22 items from four dimensions, including distribution justice, procedural justice, leadership justice and information justice. A 5-point Likert scale is used for scoring, which allows individuals to express if they disagree or agree a specific statement. Moreover, "1" means strongly inconsistent, and "5" means strongly consistent. The higher score employees get, the higher level of organizational justice employees have. The value of Cronbach's $\alpha$ is 0.938 .

3.2.2 Scale of Psychological Ownership. The scale of psychological ownership used is developed by Chi et al., which is improved based on the table of Pirce et al. The table has 4 items in total. Similar to measurement table of organizational justice, the 5-point Likert scale is used for scoring as well. "1" represents strongly inconsistent, and "5" represents strongly consistent. The higher score employees get, the higher level of psychological ownership they own. The value of Cronbach's $\alpha$ is 0.783 .

3.2.3 Scale of Organizational Trust. The scale of organizational trust is developed by Robinson et al. The table totally contains 7 items. A 7-point Likert scale is used for scoring, where "1" means 
Table 1: Description of the statistical information of the sample $(\mathrm{N}=316)$

\begin{tabular}{|c|c|c|c|}
\hline Statistical variables & Item & Number of people & Ratio \\
\hline \multirow[t]{2}{*}{ Gender } & Male & 189 & $59.8 \%$ \\
\hline & Female & 127 & $40.2 \%$ \\
\hline \multirow[t]{5}{*}{ Age } & $\leq 25$ & 38 & $12.0 \%$ \\
\hline & $26-30$ & 159 & $50.3 \%$ \\
\hline & $31-35$ & 69 & $21.8 \%$ \\
\hline & $36-40$ & 37 & $11.7 \%$ \\
\hline & $\geq 40$ & 13 & $4.1 \%$ \\
\hline \multirow[t]{3}{*}{ Education level } & Bachelor & 210 & $66.5 \%$ \\
\hline & Master & 102 & $32.3 \%$ \\
\hline & Doctor & 4 & $1.3 \%$ \\
\hline \multirow[t]{5}{*}{ Job category } & Technician & 161 & $50.9 \%$ \\
\hline & Basic management & 78 & $24.7 \%$ \\
\hline & Middle management & 38 & $12.0 \%$ \\
\hline & Senior Management & 10 & $3.2 \%$ \\
\hline & Other & 29 & $9.2 \%$ \\
\hline
\end{tabular}

Table 2: Descriptive Statistics and correlations of the variables

\begin{tabular}{llllll}
\hline & $\mathrm{M}$ & $\mathrm{SD}$ & 1 & 2 & 3 \\
\hline 1.organizational justice & 3.62 & 0.62 & & & \\
2.psychological ownership & 3.47 & 0.88 & $0.535^{* *}$ & & $0.640^{* *}$ \\
3.organizational trust & 5.32 & 1.08 & $0.673^{* *}$ & $0.546^{* *}$ & $0.531^{* *}$ \\
4.job crafting & 4.62 & 0.58 & $0.470^{* *}$ & \\
\hline
\end{tabular}

$\mathrm{N}=316,{ }^{* *} \mathrm{p}<0.01$

strongly disagree, and "7" means strongly agree. The higher score employees get, the higher level of organizational trust they have. The value of Cronbach's $\alpha$ is 0.934 .

3.2.4 Scale of Job Crafting. The scale of job crafting is developed by Slemp et al. The table totally contains 15 items from three dimensions, including task crafting, cognitive crafting and relational crafting. A 6-point Likert scale is used for scoring, where "1" means never, and "7" means always. The higher score employees get, the higher level of job crafting they possess. The value of Cronbach's $\alpha$ is 0.871 .

\section{EMPIRICAL ANALYSIS}

\subsection{Common Method Bias}

Common method bias control is a common systematic bias in questionnaire method. The common method bias was tested by factor analysis, and the results showed that the explanation rate of the 1st factor was $36.99 \%$, which was less than the critical value of $40 \%$, indicating that the test passed and the common method bias was not obvious.

\subsection{Descriptive Statistics and Correlation}

The means, standard deviations, and correlation coefficients of all variables are shown in Table 2 . There are significant positive correlations between the two variables of organizational justice, psychological ownership, organizational trust, and job crafting.

\subsection{Structural Equation Model Testing}

Using AMOS 24.0 to construct a structural equation model, the multiple chain mediation model fitted the data better $(\chi 2 / \mathrm{df}=2.520, \mathrm{RMSEA}=0.069, \mathrm{NFI}=0.959, \mathrm{RFI}=0.933, \mathrm{IFI}=0.975$, $\mathrm{TLI}=0.958, \mathrm{CFI}=0.960$ ). As shown in Figure 2, there is a significant positive effect of organizational justice perception on job reshaping ( $\beta=0.19, \mathrm{p}<0.05$ ), and hypothesis 1 holds; there is a significant positive effect of organizational justice perception on psychological ownership ( $\beta=0.58, \mathrm{p}<0.001$ ); there is a significant positive effect of organizational justice perception on organizational trust ( $\beta=0.55, \mathrm{p}<0.001$ ); there is a significant positive effect of psychological ownership on organizational trust effect $(\beta=0.32, \mathrm{p}<0.001)$; psychological ownership had a significant positive effect on job reshaping $(\beta=0.38, \mathrm{p}<0.001)$; and organizational trust had a significant positive effect on job reshaping $(\beta=0.23, \mathrm{p}<0.01)$.

\subsection{Testing for Multiple Chain Mediation Effect}

Bootstrap method was used to test the mediation effect of the model with a sample size of 5000 and a confidence interval of $95 \%$. The results are shown in Table 3 the direct effect of organizational justice on job reshaping was 0.135 with $95 \%$ confidence interval $[0.021,0.250]$, indicating that the direct effect was significant and hypothesis $\mathrm{H} 1$ was valid; the mediating effect of psychological ownership was 0.163 with $95 \%$ confidence interval [0.104,0.232], indicating that the mediating effect was significant and $\mathrm{H} 2$ was 


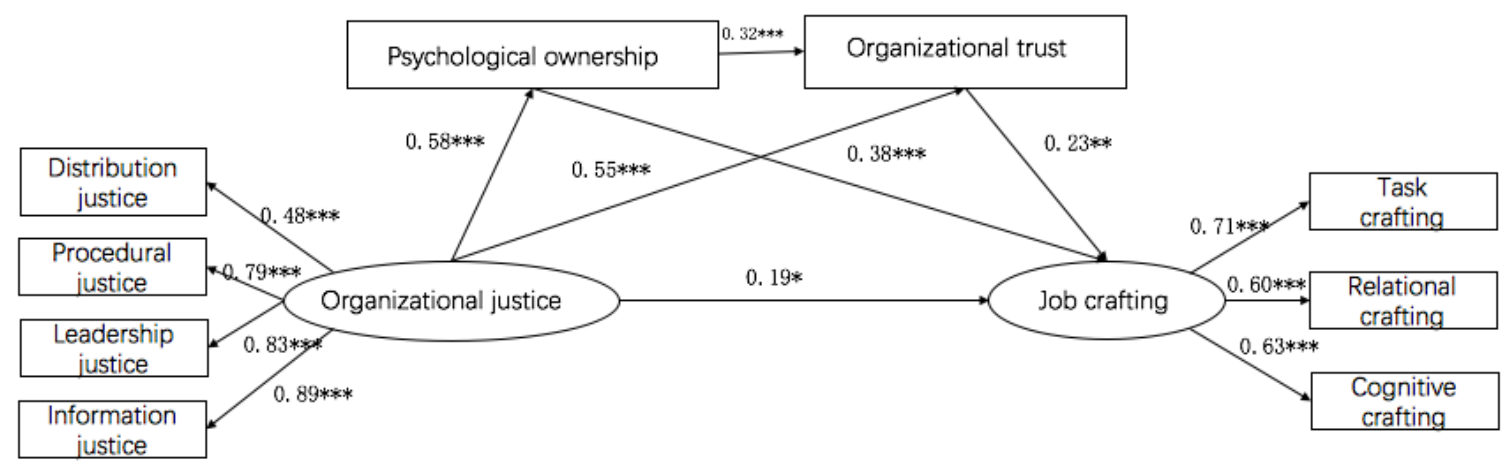

Figure 2: Structural equation model

Table 3: Testing for mediation effect

\begin{tabular}{llll}
\hline & Effect & BootLLCI & BootULCI \\
\hline Total Effect & 0.441 & 0.349 & 0.533 \\
Direct Effect & 0.135 & 0.021 & 0.250 \\
$\mathrm{OJ} \rightarrow \mathrm{PO} \rightarrow \mathrm{JC}$ & 0.163 & 0.104 & 0.232 \\
$\mathrm{OJ} \rightarrow \mathrm{OT} \rightarrow \mathrm{JC}$ & 0.099 & 0.042 & 0.166 \\
$\mathrm{OJ} \rightarrow \mathrm{PO} \rightarrow \mathrm{OT} \rightarrow \mathrm{JC}$ & 0.045 & 0.019 & 0.080 \\
\hline
\end{tabular}

valid; the mediating effect of organizational trust was 0.099 with $95 \%$ confidence interval $[0.042,0.166]$, indicating that the mediating effect was significant and $\mathrm{H} 3$ was valid. $\mathrm{H} 3$ holds; the chain mediating effect of psychological ownership and organizational trust in the relationship between organizational justice and job reshaping is 0.045 , with $95 \%$ confidence interval $[0.019,0.080]$, indicating that the above two variables have a chain mediating effect, and $\mathrm{H} 4$ holds.

\section{CONCLUSION}

\subsection{Study Results}

Our study draws four conclusions as follow:

Organizational justice has a significantly positive effect on job crafting to knowledge workers. When the workers have a higher level of organizational justice, they tend to have a higher level of job crafting.

Psychological ownership plays a partial mediating role between organizational justice and job crafting of knowledge workers.

Similar to the psychological ownership, organizational trust plays a partial mediating role as well. Moreover, the mediating effect of psychological ownership is higher than organizational trust.

Neither organizational justice nor psychological ownership has a separate effect between organizational trust and job crafting. Furthermore, organizational justice can affect organizational trust by changing the level of psychological ownership, and the chain mediating effect of improving job crafting is established.

\subsection{Theoretical Contributions}

In theory, firstly, our study enriches the research on the antecedents of job crafting. Previous studies pay more attention to the influence of the characteristics of works and personalities on job crafting, while this paper deeply discusses the mechanism of organizational environment on job crafting to knowledge workers. For an organization, the intervening space of personal characteristics and work characteristics is low, therefore, it has great management value to explore the mechanism of knowledge workers' job crafting that is driven by organizational justice. Secondly, this paper constructs a chain mediating model among organizational justice, psychological ownership, organizational trust, and job crafting, which systematically reveals the mediating role between organizational justice and job crafting.

\subsection{Management Inspirations}

The exploration of mediating roles can help managers to judge and stimulate employees' motivation on job crafting, and guide knowledge workers to craft their works. To make management better, it is important to establish a fair organizational environment and cultivate the organizational justice of employees. The management inspirations are concluded from three aspects:

The organization can build a reasonable management system and corporate culture from the four dimensions of distribution justice, procedural justice, leadership justice and information justice. Therefore, employees can expect benefits and promotion space, and get support from leaders at work, which makes employees feel 
respected, prefer to trust the organization, and change work boundaries initiatively. As a result, employees could create increased value for organizations.

Employees have different kind of feelings towards organizational justice, though they are in the same organization. Therefore, it is necessary to train employees to establish a reasonable sense of organizational justice, which is not egalitarian, but recognizes the differences in abilities and reflects them in distribution and other aspects, to help employees correct their self-perception and their perception of the organization, and to improve their level of organizational justice.

Managers could allow employees to participate in the formulation of various regulations. The more understand and energy employees put into organization, the higher psychological ownership they will have. Therefore, with the strong ownership to organization, employees regard themselves as owners of the organization, instead of employment. Such sense of ownership urges employees to accelerate their job crafting processes.

\subsection{Research limitations and future prospects}

In this paper, we collect the data through employees' self-statement. Though the deviation of collecting method is controlled within an acceptable range, longitudinal research method can be used in the future.

Our study discusses the mediating effect without considering the boundary conditions. In the future, we will consider the mediating variables to elaborate the boundary conditions that influence the mechanism of organizational justice on job crafting.

\section{REFERENCES}

[1] Pan Cheng' an, Hu Han hui, Zhou Ye, 2005. A study on incentive problems of knowledge-based enterprises based on game theory [J]. China Management Science, (03):108-114.

[2] Hu Rui Ling, Tian Xi Zhou, 2015. Reconstructing work identity and meaning-a review of work reshaping research [J]. Foreign Economics and Management,37(10):69-81.

[3] Dutton W J E, 2001, Crafting a Job: Revisioning Employees as Active Crafters of Their Work[J]. Academy of Management Review, 26(2):179-201.

[4] Petrou P, Demerouti E, Schaufeli W B,2015. Job Crafting in Changing Organizations: Antecedents and Implications for Exhaustion and Performance[J]. Journal of Occupational Health Psychology, 20(4):470-80.

[5] Yepes-Baldó, M., Romeo, M., Westerberg, K., \&Nordin, M,2018. Job crafting, employee well-being, and quality of care. Western Journal of Nursing Research,40(1),52-66.

[6] Slemp G R, Kern M L, Vella-Brodrick D A,2015. Workplace Well-Being: The Role of Job Crafting and Autonomy Support[J]. Psychology of Well-Being, 5(1):1-17.
[7] Yan Peilin,2016. The impact of job reshaping on work engagement: the role of person-job matching and work meaning [J]. China Human Resource Development,2016, (19):6-13.

[8] Eva Demerouti, Arnold Bakker, Jonathon Halbesleben,2015. Productive and counterproductive job crafting: A daily diary study[J]. J Occup Health Psychol, 20(4): 457-469

[9] Hu Qiaoting, Wang Haijiang, Long Lirong, 2020. Do new employee job reinventions lead to positive outcomes? The role of leadership member exchange and individual traditionality[J]. Journal of Psychology,52(05):659-668.

[10] Liu Ying, Xu Sen, Yang Zhong,2018. Job reinvention: Theoretical lineage, research progress and localization prospect[J]. Journal of Jiang Hai, (06):88-94+254.

[11] Wang Zhen, 2020. The formation and influence mechanism of team work reshaping [J]. Advances in Psychological Science,28(03):390-404.

[12] Berg, J.M., Dutton, J.E., \& Wrzesniewski, A. Job crafting and meaningful work. In B.J.Dik, Z.S.Byrne, \&M.F.Steger (Eds.), 2013. Purpose and meaning in the workplace. American Psychological Association., 81-104

[13] Tims, M., \&Bakker, A.B,2010. Job crafting: Towards a new model of individual job redesign[J]. South African Journal of Industrial Psychology,36(2),1-9.

[14] Peter Drucker, 2006. Management challenges of the 21st century [M]. Zhu Yanbin, Translated, Beijing: Machinery Industry Press

[15] Jin Yanghua, Xie Yaoyao,2015. The impact of ethical leadership on knowledge employees' sense of justice and satisfaction[J]. Scientific Research Management,36(12):75-82

[16] Greenberg, J,1990. Organizational Justice: Yesterday, Today, and Tomorrow[J]. Journal of Management, 16(2):399-432

[17] Colquitt J A, Conlon D E, Wesson M J , et al.,2001. Justice at the millennium: a meta-analytic review of 25 years of organizational justice research. [J]. Journal of Applied Psychology, 86(3):425-445.

[18] Cohen-Charash Y, Spector P E,2001. The Role of Justice in Organizations: A MetaAnalysis[J]. Organizational Behavior \& Human Decision Processes, 86(2):278-321.

[19] Li Rong Shu,2019. Study on the influence of organizational justice perception on job performance[D]. Liaoning University.

[20] Leventhal, G.S., Karuza, J. and Fry, W.R.1980. Beyond Fairness: A Theory of Allocation Preferences. Justice and Social Interaction, 3, 167-218.

[21] R. J. Bies, J. S. Moag, 1986, Interactional Justice: Communication Criteria of Fairness $。$ Research on Negotiation in Organization, Vol.1,43-55.

[22] Greenberg, Jerald,1993 The Social Side of Fairness: Interpersonal and Informational Classes of Organizational Justice[J]. R Cropanzano Justice in, 79-103.

[23] Liu Ya, 2002. The structure of organizational equity perception and its relationship with organizational effectiveness variables [D]. Huazhong Normal University.

[24] Pierce J L, Kostova T, Dirks K T,2001. Toward a Theory of Psychological Ownership in Organizations[J]. Academy of Management Review, 26 (2) :298-310.

[25] Yuan Ling, Huang Jian, Yao Ji Biao, 2012. An empirical study on the impact of psychological ownership on knowledge-based employee loyalty [J]. Soft Science, 26(09):110 113.

[26] Qiu M, Hu B, 2015. Study on the relationship between internal/external motivation, psychological ownership and employee engagement [J]. Soft Science,29(12):87 91.

[27] Li Xi yuan, Shi Fan, Liang Guo et al, 2013. Mechanisms of transformational leadership on individual responsibility behavior-a model with mediated moderating effects. Technology Economics (12), 118-123.

[28] Liu YM, Li YP, 2012. An empirical study of the impact of organizational justice perception on employees' psychological ownership [J]. Financial Economics, (04):60-63.

[29] Liu Hua, 2008. Study on the influence of organizational support feeling on organizational trust, work engagement, and job satisfaction [D]. Northwestern University.

[30] Nyhan, R. C,2000. Changing the Paradigm: Trust and its Role in Public Sector Organizations[J]. American Review of Public Administration, 30(1):87-109 